\section{Notes on Contributors}

Benjamin Brinner is Chair of the Department of Music at University of California, Berkeley where he has been a professor since 1989. Trained in ethnomusicology (Hebrew University; University of California, Berkeley), he has conducted research in Indonesia and Israel since the 1980s. His particular interests are musical competence and interaction, the subjects of his book Knowing Music, Making Music: Javanese Gamelan and the Theory of Competence and Interaction (University of Chicago Press, 1995); the relationship between composition, improvisation, and hybrid musical forms; and musical cognition, especially expert memory for music. He has authored two additional books, Music in Central Java (OUP, 2007) and Playing Across a Divide: Israeli-Palestinian Musical Encounters (OUP, 2010), as well as articles in scholarly journals and the New Grove Dictionary of Music and Musicians. Prior to joining the faculty at UC Berkeley he taught in Israel.

Ross Cole graduated from Christ Church Oxford in 2009 and received a Gibbs prize for the highest overall mark in music. In 2010 he was awarded an MRes from the University of York after studying with William Brooks. He is currently an AHRC-funded $\mathrm{PhD}$ candidate at King's College Cambridge, supervised by Nicholas Cook.

Brían Hanrahan is Visiting Assistant Professor in the Department of Performing and Media Arts at Cornell University. His research focuses on the history and theory of acoustic media, German and European cinema, and Weimar culture. He is currently writing a book, The Vivid Thing in the Air: Liveness and Location on Weimar Radio, on the material aesthetics and cultural history of location broadcasting in the interwar period. He has published on subjects including microphone history, avant-garde sound montage, Walter Benjamin and E. A. Dupont.

Benjamin Piekut is Assistant Professor of Musicology at Cornell University and a historian of experimental music, jazz, and rock after 1960. He has published his research in Jazz Perspectives, The Drama Review, American Quarterly, Contemporary Music Review, Cultural Critique, and various edited collections. His book, Experimentalism Otherwise:
The New York Avant-Garde and Its Limits was published by the University of California Press in 2011. He is the editor of Tomorrow is the Question: New Directions in Experimental Music Studies (University of Michigan Press, 2014), and the co-editor (with George E. Lewis) of the Oxford Handbook of Critical Improvisation Studies (OUP, 2014).

Holly Rogers is Senior Lecturer in Music and Founding Director of the Research Centre for Audio-Visual Media at the University of Liverpool. Recent fellowships include a senior research post at Trinity College Dublin and a Fulbright scholarship at the DocFilm Institute in San Francisco. She has published on a variety of audiovisual topics and is author of Visualising Music: Audiovisual Relationships in Avant-Garde Film and Video Art (LAP, 2010) and Sounding the Gallery: Video and the Rise of ArtMusic (OUP, 2013). She is also editor of a collection for Routledge, entitled Music and Sound in Documentary Film (2014) and is currently working on a new collection entitled The Music and Sound of Experimental Cinema (2015).

Bettina Varwig is Senior Lecturer in Music at King's College London. She gained her $\mathrm{PhD}$ from Harvard University in 2007 , followed by postdoctoral fellowships at Magdalen College, Oxford and the University of Cambridge. Her main research interests concern seventeenth- and eighteenth-century German musical culture, as well as issues of reception and historiography. Her monograph, Histories of Heinrich Schütz, was published by Cambridge University Press in 2011. In 2013, she was awarded the Jerome Roche Prize of the Royal Musical Association.

Tom Western is a $\mathrm{PhD}$ student in Music at the University of Edinburgh, writing up his dissertation on field recording and the uses of recorded sound to construct national identity in post-war Britain. He was awarded the British Forum for Ethnomusicology prize for best student paper at the annual conference in 2013, has conducted fieldwork in the Outer Hebrides, and his work is supported by the AHRC, which funded four months of archival work at the Library of Congress, Washington, DC, as part of its International Placement Scheme. 